\title{
COMPETÊNCIA CULTURAL E COMPETÊNCIA LINGUÍSTICA NA FORMAÇÃO DE TRADUTORES E INTÉRPRETES: DOIS CONCEITOS DISTINTOS?
}

\author{
João Azenha Junior
}

\begin{abstract}
Começo este breve estudo por tomar emprestado a Kupsch-Losereit (2002) uma tentativa "suada", como ela mesma afirma em seu ensaio, de definir competência cultural:
\end{abstract}

\begin{abstract}
...competência cultural, então, compreende tanto o conhecimento de duas ou mais culturas diferentes, já que língua e cultura coincidem na comunicação, como também a capacidade de tomar decisões translatórias, que façam jus aos pressupostos da experiência e aos conhecimentos culturalmente específicos dos leitores do texto de partida (TP) e de chegada (TC). A competência cultural daquele que traduz ou interpreta (o "translador") baseia-se numa compreensão de cultura que, no caso ideal, compreende a totalidade do pano de fundo corográfico e civilizatório da comunidade da língua de partida (LP) e de chegada (LC), a totalidade das ações e representações sociais relevantes para a comunicação, das divergências culturais nos domínios da vida cotidiana, da interação social bem como do conhecimento denotativo e enciclopédico culturalmente marcado. Cultura é compreendida, portanto, como um complexo de ações sociais (arte, religião, ciência, ética), significados e ideias; é compreendida como um sistema de formas e símbolos compartilhados. E como a comunicação mal sucedida geralmente está relacionada com a transmissão de estilos de interação, padrões, esquemas e interpretações da cultura própria, a competência cultural do tradutor ou do intérprete está baseada, além disso, na reflexão acerca das condições culturais e estruturas de comunicação que lhe são próprias: afinal, a translação presta-se à derrubada de barreiras de compreensão e a evitar dificuldades de compreensão do receptor do texto de chegada, crescido no interior de outra comunidade cultural e linguística. (p. 97; grifos meus) ${ }^{1}$
\end{abstract}

Na citação escolhida, é clara a moldura conceitual a partir da qual a definição da autora é derivada: a vertente cultural e funcional dos Estudos da Tradução, tal como desenvolvida desde meados dos anos de 1970 na Alemanha, mais especificamente pelo grupo de Heidelberg. É daí, inclusive, que vem a designação "translação", entendida como termo guarda-chuva para a interpretação (oral) e a tradução (escrita), que dá ensejo ao surgimento dos substantivos "translador" (aquele que traduz ou interpreta) e "translado" (o resultado desse processo). Também é desta matriz que vem um conceito

\footnotetext{
${ }^{1}$ Salvo indicação em contrário, todas as traduções das citações são minhas.
} 
AZENHA JR. - Competência cultural e competência linguística...

amplo de cultura, designado à época como etnográfico por Snell-Hornby (1988) e reformulado por Assmann (2010) em basicamente duas das seis acepções que o conceito de cultura pode assumir para esta última:

(...) numa outra acepção, o conceito de cultura refere-se a grandes conglomerados geográficos e políticos tais como nações com diferentes desenvolvimentos históricos, cuja unidade é garantida por línguas, mentalidades, formas de vida e de arte determinadas. Aquilo que mantém coeso o grande conglomerado é expresso pelo conceito genérico de cultura. Nesse sentido, falamos de uma cultura alemã, francesa, americana, chinesa, ou mesmo de uma cultura ocidental, sendo que, em qualquer caso, o princípio da delimitação [do espaço geográfico e político] é aquele que fundamenta totalidades dessa natureza. (p. 13)

E mais:

(...) existe ainda outro conceito (...) de cultura, que ganhou força especialmente nas últimas duas décadas. Nesse sentido, cultura é tudo o que resulta e está presente na convivência entre as pessoas. O filósofo Bernhard Waldenfels escreve que sob o conceito de cultura se pode abarcar tudo o que as pessoas fazem de si e das coisas e o que vivenciam ao fazê-lo; incluídos aí estão as interpretações simbólicas, rituais coletivos, estilos de arte ou instituições sociais, bem como o mundo da tecnologia e da mídia que se interpõe de forma continuamente crescente. (p. 13)

Não cabe aqui esmiuçar em detalhe as considerações de Assmann, inclusive no que elas têm a criticar nessas duas acepções tão genéricas e, em grande parte, subjetivas. Basta dizer que, na primeira, a autora comenta que, em geral, o que se tem como próprio de certa cultura é resultado de uma percepção externa, que pode ser revertida para outras imagens, no momento mesmo em que o observador "lança um olhar mais apurado sobre o conjunto, ou nele se insere" (id ibidem). Quanto à segunda, o risco seria o da não especificidade, um "vale tudo" que faria o conceito de cultura "degenerar-se em um clichê tautológico" (id ibidem).

Seja como for, essas talvez sejam as duas acepções de cultura mais frequentemente invocadas quando se tem em mente o desenvolvimento de uma competência cultural.

Nesse sentido, a definição de Kupsch-Losereit, apresentada no início dessas reflexões, lança alguma luz sobre a indefinição acerca do que se entende por competência cultural, muitas vezes identificada apenas com vivência, experiência pessoal, conhecimento de temas da atualidade, consciência da perspectiva histórica, conhecimentos gerais e específicos das culturas, dentre outros, a partir do que tal competência só seria construída mediante um contato efetivo, concreto, por assim dizer, 
AZENHA JR. - Competência cultural e competência linguística...

com o espaço cultural a ser conquistado. Em poucas palavras: da noção de competência cultural associada a algo não mediado pela linguagem surgiria a crença de que tal competência constitui uma instância materializada e externa à língua; um bem tangível, passível de ser apoderado.

Contudo, entendida a formulação nos termos da comunicação e de uma noção de cultura norteada pelos parâmetros oferecidos por Assmann (2010), cultura e língua aparecem associadas de forma indissolúvel, coincidentes mesmo. Essa associação, por sua vez, tampouco é evidente, ou forte o suficiente para alterar uma convicção consensual, segundo a qual a "cultura", como visto acima, assumiria um caráter material muito mais pronunciado do que a "língua". Na melhor das hipóteses, é possível enxergar a competência cultural, neste caso, como associada a tudo o que constitui o que se poderia chamar de referencial cultural, outro conceito sem contornos definidos, de múltiplas facetas, com o que mantemos uma relação que é, essa sim, mediada pela língua.

Mesmo nesse caso, a noção de língua continua restrita ao seu papel de instrumento voltado ao conhecimento desse referencial cultural, mas não como materialização, no plano linguístico, da cultura ela mesma que, por sua vez, manifestase na língua e através dela. Uma espécie de via de mão dupla, em que as duas facetas de um mesmo fenômeno se condicionam reciprocamente.

À primeira noção, aquela que separa língua e cultura, estaria associada um conceito de produção de sentido que tende a buscar correspondentes entre itens da realidade "exterior" e fenômenos linguísticos a eles relacionados "dentro da língua”; um exercício que coloca o sujeito enunciador a transitar entre esses dois mundos, o real e o linguístico, e de onde se pode derivar, com facilidade, uma noção de tradução — seja no interior de um mesmo sistema, seja entre sistemas linguísticos distintos — afeita justamente à busca por correspondentes e por uma fundamentação para isso, passível de confirmação no mundo real. Uma visão de linguagem, cultura e tradução de caráter mais estático, que visa à estabilidade de sentido e que está mais próxima do senso comum.

A segunda, aquela que faz coincidirem as noções de linguagem e de cultura, propõe uma revisão do papel do sujeito enunciador. Afinal, em que instância, senão nele e nos sentidos que ele produz, essa coincidência ocorreria? Tal mudança de olhar ressalta, de uma só vez, a singularidade dos produtos resultantes dessa interação e o compromisso que se sela a cada vez entre língua, sujeito e cultura com vistas à 
AZENHA JR. - Competência cultural e competência linguística...

constituição de uma ancoragem. Não mais, portanto, instâncias separadas, mas em constante mutação nos processos de produção de sentido; não mais o caráter estático, e sim a dinâmica.

Desse modo, do embate entre essas duas posições fundamentais, que marcam em processos cíclicos a historiografia da reflexão sobre tradução, podem surgir - e de fato surgem - consequências para o ensino da tradução e da interpretação. Ao desejo, se este for o caso, de se efetuar a passagem entre uma visão mais estática na produção de sentido para outra mais dinâmica, subjaz a hipótese de que competência cultural não pode ser outra coisa senão uma certa relação com a linguagem.

\section{Linguagem como representação}

Pensar o estabelecimento de um contínuo que desmaterializa as barreiras entre a linguagem, o indivíduo produtor de sentidos e o mundo não é algo novo.

A fim de recordar brevemente alguns conceitos que vinculam linguagem e pensamento, linguagem e visão de mundo, singularidade da produção de sentido e o papel do sujeito, tomo como pontos de partida alguns tópicos desenvolvidos sobre esse tema no final do século XVIII e início do século XIX na Alemanha, que - para alguns autores que estudam a historiografia da tradução (por exemplo, Snell-Hornby, 2006) configuram a noção de tradução e interpretação na Modernidade. E da variadíssima oferta de autores e reflexões, escolho aqui Schleiermacher e Wilhelm von Humboldt.

Friedrich Schleiermacher (1768-1834), teólogo protestante alemão, apresenta à Academia Real de Ciências de Berlim, em 24 de junho de 1813 (em pleno processo, portanto, da sua tradução de Platão), o Tratado Ueber die verschiedenen Methoden des Übersetzens (Sobre os diferentes métodos de traduzir). Exatamente dois séculos depois de defendido e trazido à luz, o tratado continua a ser lembrado pela conhecidíssima máxima de Schleiermacher, que contrasta basicamente duas atitudes de tradução:

Ou bem o tradutor deixa o escritor o mais tranquilo possível e faz com que o leitor vá a seu encontro, ou bem deixa o mais tranquilo possível o leitor e faz com que o escritor vá ao seu encontro. ${ }^{2}$

\footnotetext{
${ }^{2}$ Para as citações de Schleiermacher e de von Humboldt utilizo aqui a tradução de Celso R. Braida e de Susanna Kampff Lages, respectivamente, ambas enfeixadas no volume organizado por Heidermann (2010).
} 
AZENHA JR. - Competência cultural e competência linguística...

No entanto, o texto de Schleiermacher - aliás, como ele próprio afirma, só uma introdução a uma obra maior, que não foi escrita - traz muitas outras contribuições para a reflexão sobre linguagem que pretendemos aqui. Em sua defesa do método de estrangeirizar uma tradução, isto é, de apresentar o estrangeiro como algo não próprio à cultura receptora (a primeira das duas atitudes mencionadas na máxima acima), Schleiermacher parte basicamente dos seguintes pressupostos:

a) língua e pensamento condicionam-se reciprocamente:

Por um lado, cada homem está sob o poder da língua que ele fala; ele e seu pensamento são um produto dela. Ele não pode pensar com total determinação nada que esteja fora dos limites da sua língua. A configuração de seus conceitos, o tipo e os limites de suas articulações estão previamente traçados para ele pela língua em que ele nasceu e foi educado; o entendimento e a fantasia estão ligados por ela. Por outro lado, porém, cada homem de livre pensar e espiritualmente espontâneo molda também a língua. Pois, como, senão por meio dessas influências a língua teria se formado e crescido desde seu estado primitivo e rude até a formação completa na ciência e na arte? Nesse sentido, é a força viva do indivíduo que produz novas formas na matéria maleável da língua, originalmente apenas com o propósito momentâneo de compartilhar uma consciência transitória, das quais, porém, ora mais ora menos, algumas permanecem na língua e, recolhidas por outros, disseminam seu efeito formador. (2010, p. 49-51)

b) todo ato de enunciação é singular:

(...) todo discurso livre e superior quer ser compreendido de dois modos; por um lado, a partir do espírito da língua de cujos elementos ele é composto, como uma exposição amarrada e condicionada por este espírito, por este produzida e vivificada no falante; por outro lado, quer ser compreendido a partir do ânimo do falante como sua ação, como algo que apenas a partir de seu modo de ser poderia surgir assim e ser esclarecido. (2010, p. 51)

c) a língua é um "ente histórico":

E, sendo a língua um ente histórico, não pode haver autêntica sensibilidade para ela sem sensibilidade para sua história. As línguas não se inventam, e trabalhar nelas ou sobre elas de modo puramente arbitrário é sempre um disparate; as línguas se descobrem pouco a pouco, e a ciência e a arte são as forças que promovem e completam este descobrimento. Todo espírito raro, em que uma parte das intuições do povo se configura de modo peculiar em uma de ambas as formas, trabalha e atua dentro da língua em tal sentido e, também, suas obras têm poder de conter, por conseguinte, uma parte da história de sua língua. (2010, p. 65)

Da interação entre esses pressupostos temos, portanto, que as realizações da produção de sentido no interior de uma língua são únicas, posto que marcadas pelas 
AZENHA JR. - Competência cultural e competência linguística...

escolhas de um sujeito enunciador, a partir de uma oferta de possibilidades, e pela perspectiva da qual os usuários dessa língua enxergam a realidade. Além disso, observadas essas realizações num eixo horizontal, elas refletem o estágio de evolução dessa língua ao longo do tempo.

Wilhelm von Humboldt (1767-1835) retoma e amplia as considerações de Schleiermacher em sua Introdução a Agamêmnon (1816), na qual reforça o vínculo entre a perspectiva de observação do mundo e a própria língua:

(...) nenhuma palavra de uma língua é perfeitamente igual a outra. Diferentes línguas são, deste ponto de vista, somente outras tantas sinonímias: cada uma delas exprime o conceito de modo um pouco diferente, com esta ou aquela determinação secundária, um degrau mais alto ou mais baixo na escala das sensações. (2010, p. 105)

Humboldt soma a isso a noção de virtualidade do sistema e, por consequência, corrobora a noção de historicidade da língua, isto é, do registro, em cada realização, do estado de evolução dessa língua:

Não será demasiada ousadia afirmar que, em cada língua, mesmo nos dialetos dos povos mais rudes que sequer conhecemos suficientemente (...) se possa exprimir Tudo, as coisas mais altas e profundas, as mais fortes e delicadas. Só que estes sons permanecem sopitados como se estivessem no interior de um instrumento musical não tocado até que a nação saiba despertá-los. (2010, p. 107)

E, ao introduzir a noção de representação, de desmaterialização da realidade e de sua reconstrução no interior da tessitura discursiva, reforça a singularidade da produção de sentido ocorrida no sujeito e por intermédio dele:

Todas as formas linguísticas são símbolos e não, as próprias coisas. Não são signos convencionais, mas sons que com as coisas e os conceitos representados se encontram numa verdadeira relação - se podemos chamá-la assim - mística, uma relação mediada pelo espírito do qual surgiram e continuam a surgir; sons que por assim dizer contêm os objetos da realidade dissolvidos em ideias e, de um modo que devemos considerar ilimitado, podem modificar, determinar, separar e estabelecer relações. A esses símbolos pode ser atribuído um sentido mais alto, profundo e delicado, o que ocorre somente quando são pensados, expressos, apreendidos e reproduzidos em tal sentido. (2010, p. 107-109)

A língua aparece, então, não como produto (ergon), mas como processo (energia); não como locus em que se cristalizam experiências, mas meio em que essas experiências se reconfiguram continuamente pela ação de um sujeito, condicionam outras experiências e voltam a se transformar em signos. Assim vista, a língua não é objeto a se dominar, mas algo com que interagir. 
AZENHA JR. - Competência cultural e competência linguística...

Com as reflexões de Schleiermacher e von Humboldt estariam afinadas, também, as descobertas de Freud, algumas décadas mais tarde, acerca do processo de conhecimento de mundo, de armazenamento e recuperação de experiências. ${ }^{3} \mathrm{Na}$ passagem do século XIX para o século XX, então, ao menos de um ponto de vista filosófico, se podemos formular assim, língua, sujeito e realidade estariam intrinsecamente associados no processo de construção do conhecimento e de produção de sentido.

\section{Retrocesso e retomada}

A partir de meados do século XX, a retomada mais sistemática da reflexão sobre tradução começa associada aos primeiros experimentos com a tradução realizada e assistida por máquinas e acompanha de perto os progressos da pesquisa linguística.

Nesse contexto, a busca pela gênese do sentido a partir da decomposição e exploração de estratos constituintes do plano da forma e o do conteúdo reintroduz a discussão por uma objetivação do sentido e reacende a crença de que a um significante estaria associado um significado, de forma perene e imune às defasagens do tempo e do espaço. A essa associação corresponde um retorno à noção de mecanicidade do traduzir, segundo a qual a substituição de significantes levaria automaticamente ao transporte de significados. E dessa visão marcada pela estaticidade ressurge com força plena a noção de equivalência.

É assim que, na definição de tradução, lemos em Catford (1980[1965]), por exemplo:

A substituição de material textual numa língua (LF) por material textual equivalente noutra língua (LM). (p. 22)

E em Koller (1972):

Do ponto de vista linguístico, a tradução pode ser descrita como recodificação ou substituição: elementos a1, a2, a3 ... do inventário de signos da L1 são substituídos por elementos b1, b2, b3 ... do inventário de signos linguísticos da L2. (p. 69s)

Não é difícil ver que, a despeito da valiosa contribuição dessa vertente de pesquisa para os estudos descritivos e contrastivos das línguas, o resultado foi um efeito

\footnotetext{
${ }^{3}$ Refiro-me em especial ao estudo inaugural de Freud Zur Auffassung der Aphasien - eine kritische Studie (Para uma concepção das afasias - um estudo crítico), de 1891. Para um aprofundamento acerca deste tema, cf. ROSSI (2012).
} 
AZENHA JR. - Competência cultural e competência linguística...

colateral (hoje) indesejável: a forte ênfase depositada sobre o texto de partida incentiva uma atitude normativa e prescritiva, tanto na realização, quanto na crítica e no ensino de tradução. Além disso, subjaz a tudo a dissociação entre a chamada realidade linguística e extralinguística, num movimento e num quadro conceitual contrários àquele que fecha o século XIX.

Em meados dos anos de 1970, aproximadamente, ocorre uma mudança de paradigma denominada na Linguística de "virada pragmática" e marcada, nos Estudos da Tradução, pela vertente cultural-funcional, iniciada na Alemanha, e pelos Estudos Descritivos da Tradução desenvolvidos em Israel ${ }^{4}$.

Em poucas palavras, a ênfase da reflexão sobre tradução desloca-se do texto de partida e de uma noção de tradução como substituição e equivalência para a recepção da tradução, sua função no ambiente de chegada, sua sujeição a várias condicionantes normas, convenções, comportamentos, entre outras - e à influência de agentes quem pede, quem faz, quem deve receber a tradução, entre outros. Além disso, da herança do século XIX é retomada a noção de contínuo, que favorece uma vez mais uma revisão da dissociação operada entre a realidade linguística e extralinguística. Snell-Hornby (1988, p. 43s) resume em quatro pontos as características principais dessa vertente:

O que é dominante nas três novas abordagens básicas recentemente apresentadas na Alemanha (Hönig e Kußmaul, 1982; Reiß e Vermeer, 1984 e Holz-Mänttäri, 1984) é, primeiramente, a orientação mais para a transferência cultural do que para a transferência linguística; em segundo lugar, esses autores veem a tradução não como um processo de transcodificação, mas como um ato de comunicação; em terceiro, todos eles se orientam mais para a função do texto de chegada (tradução prospectiva) do que para as prescrições do texto de partida (tradução retrospectiva); e em quarto, eles veem o texto como parte integrante do mundo e não como um espécime isolado de linguagem. (grifos da autora)

E em Reiss e Vermeer (1984, p. 26), lemos:

Uma língua (...) é elemento de uma cultura. A língua é o meio convencional de comunicação e de pensamento de uma cultura. Cultura é a norma social válida numa sociedade e é também sua expressão.

\footnotetext{
${ }^{4}$ Abordei esse tema de forma mais detalhada em Azenha 2008 e 2010.
} 
AZENHA JR. - Competência cultural e competência linguística...

A influência da teoria da comunicação associada a uma noção etnográfica de cultura, enquanto moldura no interior da qual se insere toda a comunicação mediada pela tradução, consagram o reconhecimento de que toda e qualquer ação de produção de sentido em linguagem está enraizada num solo do qual depende para existir:

A sociocultura é a raiz de toda manifestação linguística e determina em grande parte sua forma. Quem quiser, portanto, "atacar o problema pela raiz", não deve se orientar apenas pela parte visível do texto — tronco, galhos e folhas, por assim dizer —, mas deve estar em condições de avaliar o aspecto geral do texto com base nos pressupostos socioculturais. (Hönig e Kussmaul, 1982, p. 45; grifos dos autores)

A reintrodução desses elementos, assim como os avanços da perspectiva psicanalítica e desconstrutivista dos Estudos da Tradução, resgata e reabilita, então, as conquistas preconizadas até fins do século XIX por teóricos da tradução e filósofos da linguagem.

Nesse sentido, podemos sintetizar assim um estado de coisas no que respeita às relações entre língua, sujeito e mundo: se a assim chamada realidade objetiva é primeiramente dissolvida para ser reconstruída no discurso; se essa reconstrução é fruto de um ato de enunciação singular, mediado por um sujeito ancorado no tempo e no espaço; se o meio em que isso se dá - as línguas — é, ele mesmo, um fato histórico; se, em decorrência disso, as línguas incorporam diferentes perspectivas no modo como seus usuários veem o mundo; e se, por fim, essas perspectivas encontram uma formulação (linguística) condizente com o estágio de evolução das línguas, então as noções de competência linguística e competência cultural, que nos interessam aqui, precisam ser reformuladas não como entidades dissociadas, mas como duas faces de uma mesma moeda.

\section{Enxergar o mundo na(s) língua(s) e vice-versa}

Enquadradas nessa moldura, língua e cultura geram para a tradução uma matriz singular, a partir da qual o sujeito produtor de sentido pode agir num lapso de tempo situado entre a mirada retrospectiva para o texto de partida e a mirada prospectiva para as condições de recepção, e na qual lhe é assegurada a premissa fundamental de tomar para si e em si, a cada vez, a tarefa de concretizar no produto do seu trabalho o contínuo que concilia língua e mundo.

Se isso parece pressupor um sólido nível de conhecimento, construído ao longo de muito tempo de lida com questões de tradução, a experiência ensina que aspectos 
AZENHA JR. - Competência cultural e competência linguística...

culturais atrelados à língua numa perspectiva contrastiva podem surgir já no momento mesmo do aprendizado de uma estrutura desconhecida na língua estrangeira (LE), ou mesmo na reflexão sistemática sobre estruturas já conhecidas dessa língua, suscitada pelo exercício da tradução.

Se tomarmos, por exemplo, o par de línguas alemão/português, podemos pensar na formação continuada de um conhecimento desse complexo língua/cultura baseada na construção de um olhar que favorece menos a dissociação e mais a interação entre as duas faces desse complexo. Assim, as diferenças entre gêneros gramaticais podem ser vistas como elemento complicador para a memorização do léxico, mas também podem ser consideradas a partir de sua relação com o imaginário das culturas (o sol feminino e a lua masculina, em alemão); na morfologia, podemos enxergar a composição de palavras em alemão como um mecanismo que visa à concisão e à economia, mas também como forma eficaz de circunscrever e de atribuir concretude a conceitos, intensificada por recursos de nominalização de verbos e de atributos que, igualmente, atribuem concretude a ações e qualidades; podemos aprender a montar a voz passiva em seus múltiplos empregos, mas também podemos pensar no impacto do seu uso sistemático para a despersonalização do estilo, sobretudo se associada aos mecanismos de nominalização mencionados acima (um traço linguístico, aliás, muito presente nas linguagens de especialidade). Do mesmo modo, as fórmulas de tratamento também podem ser vistas como espelhos de diferentes relações de formalidade e informalidade, os verbos modais como formas de polidez e de sustentação de formulações indiretas empregadas em situações diferenciadas nos dois complexos em contraste, a diferente estruturação interna de gêneros discursivos específicos como determinantes de ênfases diferenciadas a tópicos diferenciados (as partes de um contrato de prestação de serviços, por exemplo, ou a estruturação de bulas de remédios, sujeitas a legislações diferenciadas), as diferenças nas estruturas argumentativas e na sua estruturação lógica do discurso como indicativas de formas diferentes de negociar (afirmar para só então justificar ou o inverso), o emprego de formas específicas de discurso para marcar o envolvimento do sujeito que enuncia, ou então seu distanciamento ou comentário.

São só alguns exemplos e em todos eles sobressai-se o emprego do atributo "diferente". Isso aponta, como vimos, para uma perspectiva contrastiva, que a sala de aula de tradução e de interpretação pode recobrar agora, transcorrida a fase do ensinoaprendizagem de uma língua estrangeira a partir de um ângulo comunicativo e considerados os avanços da reflexão sobre tradução e de áreas fronteiriças, sem o ranço 
AZENHA JR. - Competência cultural e competência linguística...

da busca por equivalências formais; sem o temor, portanto, de retroceder a um estágio governado por uma visão estática de produção de sentido em linguagem e em tradução, mas no interior de um quadro que coloca essas relações numa perspectiva sociológica, pragmática e funcional.

Kupsch-Losereit (2002) apresenta cinco componentes de um módulo denominado "competência cultural" a compor o currículo da formação de tradutores e intérpretes. Do ponto de vista teórico, esses componentes são orientados por vertentes diversas - a semântica do scene-and-frames, a análise do discurso, a pragmática contrastiva, a hermenêutica, a psicolinguística, a linguística cognitiva e os Estudos da Tradução - e, metodologicamente, restringem-se àqueles aspectos associados a um círculo cultural ou a um par de línguas, de um lado, e ao processo de traduzir, de outro.

Três desses componentes dizem respeito à construção de uma base de conhecimentos apoiada em três pilares: o conhecimento específico de uma cultura linguística, o conhecimento comunicativo-procedimental e o conhecimento textual. Os outros dois componentes referem-se ao que a autora chama de "suposições prognósticas do tradutor ou intérprete" e suas "estratégias cognitivas". Passo em revista brevemente esses cinco componentes, a fim de mostrar que a construção dessa competência, na proposta da autora, se dá na língua e através dela.

Para a construção do conhecimento específico de uma cultura linguística, entram em jogo, basicamente, a sensibilização para diferentes conceituações e diferentes referenciais de conhecimento que têm, nas diferentes línguas/culturas, representações (scenes) diversas. É o caso, já conhecido, de conceitos que, possuindo uma mesma designação para um espaço linguístico amplo (dos falantes de inglês, por exemplo, em suas muitas variáveis), são interpretados de modo diverso por diferentes setores desse espaço linguístico, ou recobrem segmentos diferentes no plano conceitual. Incluem-se aqui, também, a incorporação, pela linguagem comum e de especialidade, de referências literárias, os Realia marcados socioculturalmente, as interpretações de símbolos e as formas de expressão simbólicas (como o emprego simbólico das cores, por exemplo), entre outros. Conhecimento específico de uma cultura linguística entendido, portanto, como a habilidade de reconhecer cultura na língua.

O conhecimento comunicativo-procedimental envolve o conhecimento de normas, convenções, tradições, papéis sociais e formas de tratamento, entre outras, que se espelham, no plano da língua, em 
AZENHA JR. - Competência cultural e competência linguística...

atos de fala como pedir, exigir, ordenar, desculpar, prestar esclarecimentos, recomendar, desaconselhar, cumprimentar, argumentar ou negociar, [que] são convencionalmente compartilhados e associados a sujeitos e a pressupostos sociais. (Kupsch-Losereit, 2002, p. 98)

Mais uma vez, não se trata aqui de um estudo em separado de fenômenos linguísticos, mas sim da habilidade de reconhecer em formulações linguísticas traços comportamentais e valores que governam a comunicação em suas múltiplas manifestações.

No conhecimento textual está envolvida a educação do olhar para tipos de textos que apresentam diferenças em todos os níveis da análise linguística, assim como no uso de recursos não verbais: contratos, patentes, sentenças judiciais ${ }^{5}$, instruções de uso ${ }^{6}$, dentre tantos outros. Inclui-se aqui, segundo Kupsch-Losereit (2002), também o emprego de recursos linguísticos como fraseologismos e ditos populares, nos casos em que a estruturação dos tipos de texto, assim como a argumentação neles desenvolvida, faz referência (ou não) a tradições ancestrais (por exemplo, na cultura chinesa), o que contrasta com a estruturação e a argumentação mais "sóbrias" desses mesmos tipos de textos numa cultura como a alemã.

Os três tipos de conhecimento, na verdade separados apenas para a clareza da exposição, são também o ponto de partida para as chamadas "suposições prognósticas" e para as "estratégias cognitivas" de tradutores e intérpretes. Nesses dois últimos dos cinco componentes apresentados pela autora, entram em jogo na elaboração do produto da translação (o translado), além dos conhecimentos linguístico-culturais apontados acima, também projeções do cenário de recepção que impõem ajustes e mecanismos de monitoramento, cujo objetivo é direcionar a recepção e evitar o resvalo para estereótipos arraigados. É o momento final da restituição do contínuo que separa dois momentos - o da produção do texto de partida e o da produção do texto de chegada —, em que estratégias discursivas empregadas na forma de comentários e expansões garantem total visibilidade ao tradutor e ao intérprete na tentativa de vencer o hiato que separa esses dois momentos (por exemplo, a contextualização de um comentário ou de uma piada que possam causar constrangimento no receptor).

\footnotetext{
${ }^{5}$ Para um aprofundamento acerca de condicionantes culturais na configuração do discurso jurídico, cf., por exemplo, Reichmann 2009.

${ }^{6}$ Cf. Azenha 1999.
} 
AZENHA JR. - Competência cultural e competência linguística...

Vemos, por essa breve exposição, que o desafio a que se alude aqui pode ser sintetizado menos numa noção quantitativa de conhecimento acumulado, e mais no modo como se estabelece a relação do aprendiz ou do profissional da tradução e da interpretação com o objeto-meio de seu trabalho, a língua. Em vista da constância e do caráter ininterrupto dos movimentos de evolução das línguas, essa relação há de ser constantemente revista e atualizada, o que coloca para a formação desse profissional o compromisso de centrar seus eixos sustentadores não no estabelecimento de um patamar de domínio, mas sim na conscientização e na instrumentalização.

\section{Algumas consequências para a formação}

Uma primeira consequência decorrente das considerações apresentadas acima, e talvez a mais importante, diz respeito ao fato de que tradutores e intérpretes trabalham com representações da realidade. Isso significa, primeiramente, que em seu objeto de trabalho — os textos em situação — está formalizada uma visão profundamente comprometida com um referencial cultural, de que é, ao mesmo tempo, espelho e condicionante. E aqui não há exceção: esse comprometimento está presente, em graus diferenciados, tanto para a literatura, como para as linguagens de especialidade; tanto para o ambiente escrito, quanto para o verbal oral.

Uma segunda consequência refere-se ao fato de que tradutores e intérpretes, por sua vez, imprimem ao seu objeto de trabalho uma perspectiva marcada pelo modo através do qual cada um enxerga o mundo e pelas condicionantes que envolvem a realização de cada tarefa de tradução em particular. Isso inclui tanto qualidades louváveis, sedimentadas por força da experiência, quanto vícios adquiridos na lida com os ditames do mercado.

Essas duas perspectivas lançam à formação de tradutores e intérpretes vários desafios, dentre os quais o maior deles talvez seja o tratamento não dissociado de teoria e prática.

Se, de um lado, é consenso que a formação desses profissionais não pode se dar sem o apoio da teoria, por outro, a experiência da sala de aula revela o quanto é difícil transportar para as atitudes de tradução e para os comentários acerca de uma tradução conceitos e procedimentos metodológicos aprendidos "em separado", seja no interior de uma visão diacrônica dos Estudos da Tradução, seja numa perspectiva sincrônica. Exemplo disso são estudantes que se destacam nas aulas de teoria, detêm um elevado grau de domínio das suas línguas de trabalho, mas não conseguem - em suas 
AZENHA JR. - Competência cultural e competência linguística...

manifestações sobre seus trabalhos ou o de seus colegas — resistir à tentação de adotarem, consciente ou inconscientemente, uma perspectiva que separa indivíduo, língua e mundo e que os leva a ocuparem um local discursivo "isento", que revalida uma concepção de tradução centrada na equivalência lato sensu.

Se, por outro lado, a formação desses profissionais concentra-se quase que exclusivamente numa visão instrumental de linguagem, voltada a propósitos imediatistas, focalizada no desempenho e calcada no pressuposto do domínio das línguas envolvidas, o risco acaba sendo o mesmo: a língua tenderá a ser vista como entidade a ser conquistada de uma perspectiva estrutural e quantitativa e a chamada competência cultural como fruto da experiência acumulada, vivenciada aparentemente fora da linguagem.

Reconheço que os contornos diversos nos objetivos dos cursos de formação de tradutores e intérpretes impõem decisões que dificultam um trabalho mais prolongado com essas questões. Ao mesmo tempo, não consigo enxergar como a formação de tradutores e intérpretes possa prescindir de um trabalho sistemático e, ao mesmo tempo, delicado com essas questões de linguagem, cujo resultado não pode ser aferido em curto prazo, se quiser transformar em estratégias didáticas eficazes uma série de avanços obtidos no plano da reflexão sobre tradução nas últimas quatro décadas.

Minha experiência com a formação de tradutores ensina o quanto é produtivo e recompensador para o tradutor público e intérprete comercial, por exemplo, frequentar uma disciplina de tradução literária; inversamente, o quanto tradutores literários têm a ganhar cursando uma disciplina voltada à tradução de textos técnicos, ou então um módulo introdutório à interpretação. A experiência de vivenciar um "outro lado" do traduzir contabiliza ganhos que não dizem respeito apenas ao arredondamento de uma visão de linguagem, tal como proposta aqui, mas também ao treino de uma habilidade que tanto condiciona seu trabalho: a administração da variável tempo e a mudança de suporte para o trabalho (do meio escrito para o oral e vice-versa), associada ao aspecto qualitativo do trabalho. A ampliação da base de conhecimento assim gerada confere a tradutores e intérpretes dispostos a repensar sua relação com a linguagem mecanismos de controle e monitoramento que o auxiliam, de um lado, a aperfeiçoar as chances de uma recepção adequada de seu trabalho e, de outro, a minimizar os riscos de resvalarem para estereótipos nas suas “suposições prognósticas” (Kupsch-Losereit, 2002, p. 6).

Assim, parece-me justificado, ao longo do curso de formação de tradutores e intérpretes, garantir um espaço de reflexão e de trabalho no sentido de aproximar essas 
AZENHA JR. - Competência cultural e competência linguística...

duas competências, a cultural e a linguística, só aparentemente dissociadas. Parece-me justificado, enfim, firmar um compromisso - cada curso a seu modo e consideradas suas características e objetivos - com uma mudança de olhar em relação à linguagem, que auxilie tanto estudantes de tradução em fase inicial, quanto tradutores e intérpretes profissionais que buscam cursos para atualizarem seus conhecimentos, a enxergarem a língua para além de um ponto de vista meramente instrumental, isto é, para além de meio, de suporte para se atingir o objetivo (comunicativo) da interação verbal escrita (tradução) ou oral (interpretação); a enxergarem a cultura para além de um mundo à parte, a ser vivenciado apenas de maneira efetiva e concreta, tangível; e, como decorrência dessas duas premissas, a considerarem língua e cultura como vias de mão dupla em constante interação, cada uma delas sendo reflexo e condicionante da outra.

Só assim, a meu ver, fica preservada a possibilidade de se transformar a experiência acumulada (estática) em competência interativa (dinâmica); só assim é possível fazer jus a um processo constante e ininterrupto de renovação, de construção e de qualificação do conhecimento.

\section{Referências}

ASSMANN, Aleida. Einführung in die Kulturwissenschaft. Grundbegriffe,

Themen, Fragestellungen. 3, neu bearbeitete Auflage. Berlin: Erich Schmidt Verlag, 2010.

AZENHA Jr., João. Tradução técnica e condicionantes culturais. Primeiros passos para um estudo integrado. São Paulo: Humanitas, 1999.

Text Linguistics and Translation: Redefining the concept of "cultural mark". TradTerm, v. 14, p. 51-71, 2008.

- Transferência cultural em tradução: contextualização, desdobramentos, desafios. TradTerm v. 16, p. 37-66, 2010.

CATFORD, J.C. Uma teoria linguística da tradução: um ensaio de linguística aplicada (trad. do Centro de Especialização de Tradutores de Inglês do Inst. De Letras da PUC-Campinas). Campinas, SP: Cultrix/PUC, 1980[1965].

HÖNIG, H. e KUSSMAUL, P. Strategie der Übersetzung. Ein Lehr- und Arbeitsbuch. Tübingen: Narr, 1982.

HOLZ-MÄNTTÄRI, Justa - Translatorisches Handeln. Theorie und Methode. Helsinki Universität, 1984. 
KOLLER, Werner. Einführung in die Übersetzungswissenschaft. Heidelberg: Quelle \& Meyeres, 1972.

KUPSCH-LOSEREIT, S. Die kulturelle Kompetez des Translators, 2002. Disponível em: http://www.fb06.uni-mainz.de/user/kupsch/kompetenzkulturell.html.

REICHMANN, Tinka. Marcas culturais nas linguagens de especialidade. In: ROSA, L.C., SCHÖNBERGER, A. E SCOTTI-ROSIN, M. (Eds.). Lusorama. Zeitschrift für Lusitanistik. Revista de Estudos sobre os Países de Língua Portuguesa, p. 103-122, 2009.

REISS, K. \& VERMEER, H.J. Grundlegung einer allgemeinen Translationstheorie. Tübingen: Niemeyer, 1984 (Linguistische Arbeiten 147).

ROSSI, Emiliano. Tradução como sobre-vida: no exemplo de Sobre a concepção das afasias - um estudo crítico, de Sigmund Freud. São Paulo, 2012. Tese de Doutoramento. FFLCH, USP.

SCHLEIERMACHER, Friedrich (1813). Sobre os diferentes métodos de traduzir. Trad. Celso R. Braida. In: HEIDERMANN, Werner (Org.) Antologia bilíngue Clássicos da Teoria da Tradução. Volume 1 - Alemão/Português. 2 $2^{\mathrm{a}}$. edição revista e ampliada. Florianópolis: PGET/UFSC, 2010, p. 37-101.

SNELL-HORNBY, Mary. Translation Studies. An integrated approach. Amsterdam/Philadelphia: John Benjamins Publishing Company, 1988.

. The turns of Translation Studies. New paradigms or shifting viewpoints? Amsterdam/Philadelphia: John Benjamins, 2006.

VERMEER, H. J. Aufsätze zur Translationstheorie. Heidelberg, 1983.

VON HUMBOLDT, Wilhelm (1816). Introdução a Agamêmnon. Trad. Susanna Kampf Lages. In: HEIDERMANN, Werner (Org.). Antologia bilíngue - Clássicos da Teoria da Tradução. Volume 1 - Alemão/Português. 2 $2^{\text {a }}$ edição revista e ampliada. Florianópolis: PGET/UFSC, p. 103-117, 2010. 